\title{
Evaluation of clinical usefulness of the microplate agglutination test for serological diagnosis of legionella pneumonia
}

\author{
K. TATEDA, H. MURAKAMI, Y. ISHII, N. FURUYA, T. MATSUMOTO and K. YAMAGUCHI \\ Department of Microbiology, Toho University School of Medicine, Tokyo, Japan
}

\begin{abstract}
Recently, a microplate agglutination test (MPAT) was established for the serological diagnosis of legionella pneumonia. To evaluate its usefulness, this study examined antibody titres in 121 serum samples serially obtained from 40 patients with pneumonia, including 17 cases of confirmed legionella pneumonia. Six of the 17 proven cases became serologically positive within 4 weeks of the onset of pneumonia as assayed by MPAT (cut-off value: four-fold rise to $\geqslant 128$ in paired sera or $\geqslant 256$ in a single serum specimen), whereas the remaining 11 cases were serologically negative despite serial examination. Four proven cases who were treated with corticosteroids in the acute phase had antibody titres $<8$ during the first 4 weeks of infection, after which one case showed an elevation in antibody titre for the first time, 13 weeks after the onset of disease. In contrast, all non-proven cases had antibody titres of $\leqslant 64$, and only one case developed a four-fold or greater rise in titre. These results indicate that MPAT is a useful method for the laboratory diagnosis of suspected legionella pneumonia, although several falsenegative cases were observed. This suggests that the previously established MPAT criteria may require modification, possibly to slightly lower values. These data also indicate that serial examination over the first month of infection may be necessary for serodiagnosis of legionella pneumonia, especially in patients treated with corticosteroids.
\end{abstract}

\section{Introduction}

The Legionella spp. are facultative intracellular bacteria and are an important cause of epidemic and sporadic pneumonia with a relatively high mortality. Although specific diagnostic tests, such as urinary antigen detection and polymerase chain reaction (PCR) techniques, are currently available, serological tests remain an important tool for clinical diagnosis of Legionnaires' disease [1].

Various methods for the serodiagnosis of legionella pneumonia have been described. These include microagglutination [2], immune adherence haemagglutination [3], indirect haemagglutination [3], ELISA [4], the rapid microagglutination test [5] and indirect immunofluorescence assay (IFA) [6]. Of these methods, IFA is the most commonly used. However, this assay is laborious and requires skilled laboratory personnel for interpretation. Recently, a microplate agglutination test (MPAT) was established as a

Received 31 July 1997; accepted 21 Aug. 1997.

Corresponding author: Dr K. Tateda.

E-mail: kazu@sirius.med.toho-u.ac.jp commercially available kit for serodiagnosis of seven serogroups of L. pneumophila and four other species of Legionella. Yabuuchi et al. [7] used MPAT to investigate antibody titres in 178 serum samples, and determined the clinical cut-off values for this method. MPAT is considered to be a simple and inexpensive test which is well within the capability of most laboratories.

The present study was designed to evaluate the usefulness of, and clinical criteria for, MPAT. Antibody titres were examined in 121 serum samples serially obtained from 40 patients with pneumonia, including 17 cases of confirmed legionella pneumonia.

\section{Materials and methods}

Serum samples in patients with pneumonia

Clinical specimens such as sputum, bronchoalveolar lavage fluid, serum and urine from suspected cases of legionellosis were voluntarily sent to this department. Protocols were approved by the Ethics Review Board of the Toho University School of Medicine and a consent form was obtained from all subjects participat- 
ing in the study. In addition to clinical manifestations, a case of legionellosis was defined as radiographically confirmed pneumonia accompanied by at least one of the following: (i) isolation of Legionella organisms from respiratory secretions; (ii) a significant increase in serum antibody titre; (iii) detection of urinary antigen (Binax Legionella Urinary Antigen EIA, Binax, Portland); or (iv) detection of Legionella DNA by PCR [8]. In this study, 121 serum samples from 40 patients with pneumonia were stored at $-80^{\circ} \mathrm{C}$ until used. In confirmed cases of legionella pneumonia, information including basic personal data, medications, symptoms, outcome and results of specific laboratory tests were also obtained.

\section{Determination of serum antibody titre by MPAT}

Serum antibody titres were examined by MPAT (Denka-seiken, Tokyo, Japan), as described previously [7]. Briefly, serum samples were decomplemented by heat treatment $\left(56^{\circ} \mathrm{C}, 30 \mathrm{~min}\right)$ and then serially diluted in PBS from 1 in 8 to 1 in 512 in the wells of a Ubottomed microtitration plate $(25-\mu 1$ volumes). Heatkilled bacteria, including $L$. pneumophila (serogroups 1a, 1b, 2-6), L. bozemanii, L. dumoffi, L. gormani and $L$. micdadei, were prepared by incubating bacterial suspensions for $1 \mathrm{~h}$ at $100^{\circ} \mathrm{C}$, and the concentration was adjusted to an $\mathrm{OD}_{650}$ of 0.3 . Heat-killed bacterial suspensions $(25 \mu \mathrm{l})$ were inoculated into each well of diluted serum samples. The plate was incubated at room temperature for $20 \mathrm{~h}$, after which agglutination in the wells was determined. In this study, the previous criteria for positive results (titre $\geqslant 256$ in a single examination, or more than a four-fold rise to $\geqslant 128$ in paired sera) were adopted.

\section{Results}

As shown in Table 1, 17 patients had confirmed legionella pneumonia, as diagnosed by serum antibody titres (six cases), culture (two cases), detection of urinary antigen (six cases) or PCR (seven cases) or combinations of these. In contrast, positive results were not obtained in 23 patients with pneumonia despite examination by these laboratory tests. Although the possibility of infection by other serogroups or rare species of Legionella could not be completely excluded, it seemed unlikely that these patients were infected with L. pneumophila. Therefore, these patients were designated as non-confirmed cases. In confirmed cases, the aetiologic species were considered to be $L$. pneumophila in 13 cases and $L$. bozemanii in three cases, while the remaining case was designed as $L$. pneumophila or $L$. dumoffii pneumonia, because the antibody titre to both species was elevated. One patient with L. pneumophila pneumonia died; the others survived.

Fig. 1 shows the results of serum antibody testing in proven cases of legionella pneumonia. Among the 17 cases, six became serologically positive during the course of the disease as assayed by MPAT (Fig. 1a). The mean period between the onset of pneumonia and the rise in antibody titre was $24.2 \mathrm{SD} 7.6$ days. In contrast, the remaining 11 cases were considered

Table 1. Results of laboratory tests for legionella infection

\begin{tabular}{lcccl}
\hline & \multicolumn{3}{c}{ Number of positive results/number examined } \\
\cline { 2 - 5 } Cases examined (n) & Serum antibody & Culture & Urinary antigen & PCR \\
\hline Confirmed cases (17) & $6 / 17$ & $2 / 7$ & $6 / 11$ & $7 / 8$ \\
Non-confirmed cases (23) & $0 / 23$ & $0 / 12$ & $0 / 16$ & $0 / 16$ \\
\hline
\end{tabular}
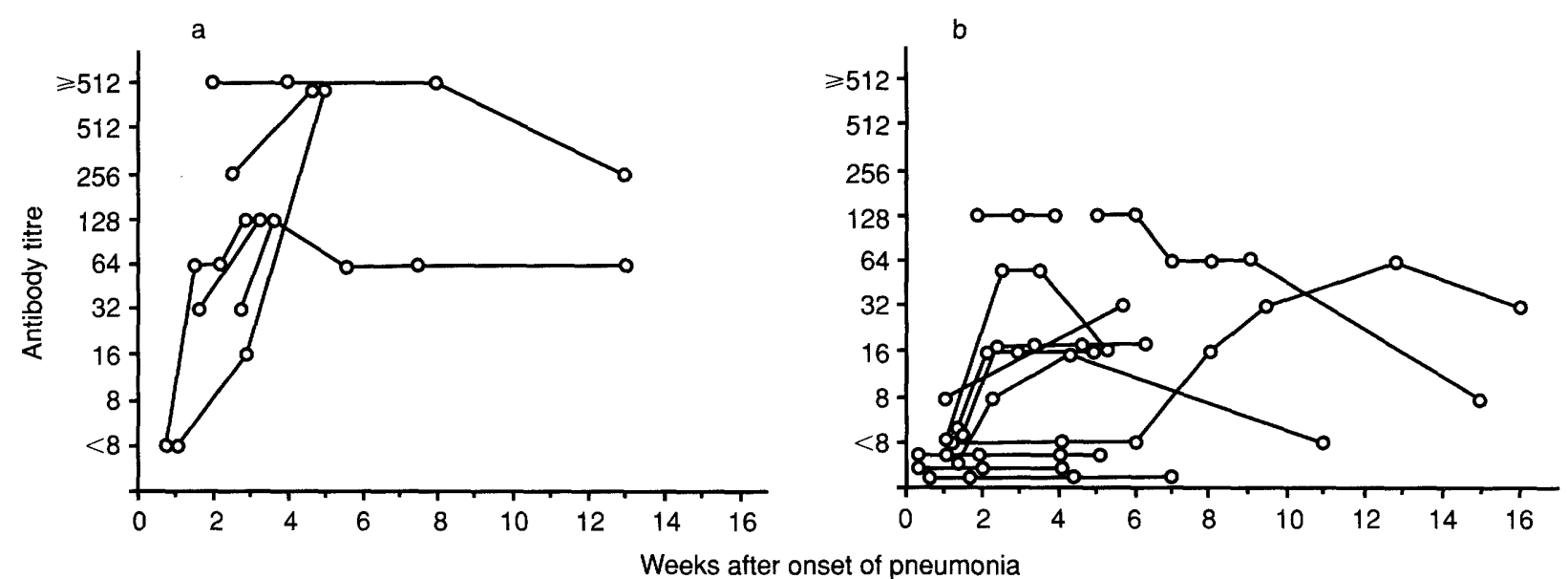

Fig. 1. Serial measurement of antibody titre in patients with legionella pneumonia throughout 16 weeks of follow-up: (a) six cases considered positive on MPAT; (b) 11 cases considered negative by MPAT despite positive results on culture, urinary antigen or PCR. Each symbol represents a single case. 
serologically negative despite serial examination of antibody titres (mean, 4.3 tests/case). In these falsenegative cases, two patients showed a peak antibody titre of 128 and another three cases showed a four-fold or higher rise in the titre, although the peak values were only 64 . Four proven cases who were treated with corticosteroids during the acute phase of the disease had antibody titres $<8$ during the first 4 weeks, after which one case exhibited an elevation in antibody titre for the first time, 13 weeks after the onset of pneumonia.

Fig. 2 shows serum antibody titres in 23 patients with non-confirmed legionellosis. The serum antibody titres were $\leqslant 64$ in all but one patient who exhibited a fourfold or greater rise in titre. These comparative data from confirmed and non-confirmed cases indicate that the previous cut-off values of MPAT may be slightly too strict for proper serodiagnosis of legionella pneumonia.

\section{Discussion}

As Legionnaires' disease is still a difficult infection to diagnose in the acute phase, serological tests on stored serum samples play an important role for retrospective examination. The IFA is widely used for the serological diagnosis of Legionnaires' disease, but it may be beyond the capacity of small laboratories. In contrast, MPAT is a simple and inexpensive test well within the capability of most laboratories. Although it takes $20 \mathrm{~h}$ to obtain the results, the end-point is more objective and reproducible than that of IFA. The test requires no expensive or sophisticated equipment and no specific expertise.

Yabuuchi et al. [7] have reported the clinical usefulness of MPAT for serodiagnosis of legionellosis. They examined a total of 178 serum samples from individuals comprising 98 healthy persons, and 80 patients with pneumonia of whom 17 had mycoplasma

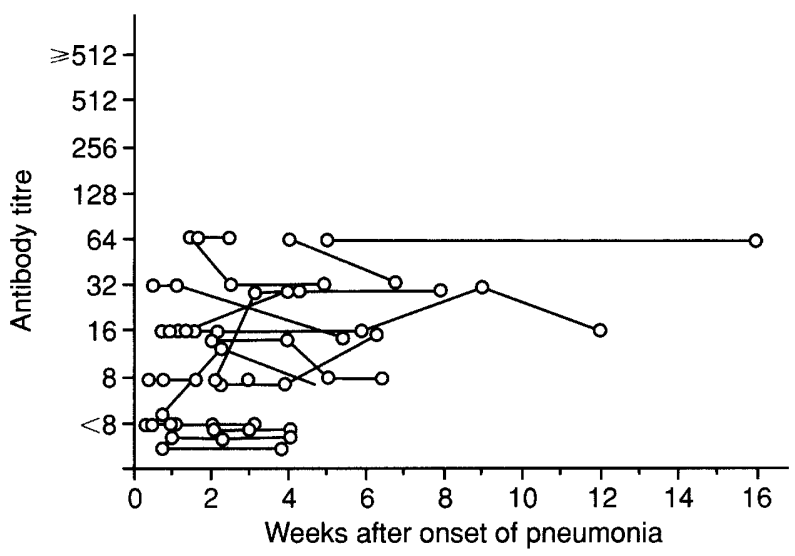

Fig. 2. Serial measurement of antibody titre in patients with pneumonia, suspected but not diagnosed as legionella pneumonia. Each symbol represents a single case. pneumonia, nine had chlamydia pneumonia and 32 had other bacterial pneumonias. After careful consideration, they determined cut-off values of MPAT. Koide et al. [9] reported comparative data from IFA and MPAT from 64 serum samples, in which MPAT was shown to exhibit excellent specificity whereas sensitivity was only $47 \%$ when the previous criteria were used. In the present study, these criteria were used to diagnose 17 patients with proven and 23 patients with non-proven legionella pneumonia. Although six proven cases clearly demonstrated serological responses to fit the criteria, the remaining 11 cases were negative on MPAT. In contrast, all nonconfirmed cases were negative despite at least four serial examinations. The data from the present study are to a large extent consistent with those of previous studies $[7,9]$, but indicate that the previous criteria may be slightly too strict, resulting in a significant number of false-negative results. This suggests that the cut-off titre for a positive MPAT may require modification, possibly to a slightly lower value, to enhance the proper serodiagnosis of legionella infection.

No serological responses were observed during the first 4 weeks of pneumonia in four patients with proven legionella pneumonia who were treated with a glucocorticoid in the acute phase. Subsequently, one patient exhibited a significant rise in antibody titre, 13 weeks after the onset of disease. As glucocorticosteroids are known to inhibit host immune responses, including antibody production, the delayed serological response was most likely due to this immunosuppressive drug. In patients with legionella pneumonia, especially cases suspected to be complicated with the adult respiratory distress syndrome (ARDS) or severe hypoxaemia, glucocorticoids may be administered as a supportive therapy. With respect to the timing of serological examination, our data have a critical clinical implication - that serial testing over a period of 1 month may be necessary for a proper serodiagnosis of legionella pneumonia, especially in patients receiving corticosteroids.

In the light of its clinical features and the frequency with which it occurs, pneumonia caused by Mycoplasma pneumoniae is the disease most likely to be confused with and misdiagnosed as Legionnaires' disease. Moreover, these two infections are seldom confirmed in the laboratory by isolation of the organisms, but are most commonly confirmed by retrospective analyses of paired serum specimens. In 1979, Grady et al. [10] reported that sera from patients with legionella pneumonia also contained antibodies to $M$. pneumoniae, although other investigators described the lack of a statistically significant relationship in seroreactivity between these two organisms [11]. In another study, MPAT analysis of serum from six of 17 proven cases of $M$. pneumoniae pneumonia demonstrated a relatively high titre (128) 
against L. pneumophila $1 \mathrm{~b}$ [7]. Recently, Lieberman et al. [12] reported 56 cases of community-acquired legionella pneumonia, in which 35 patients were infected with at least one other aetiologic organism, for example Streptococcus pneumoniae (41\%), $C$. pneumoniae $(21 \%)$ and $M$. pneumoniae $(27 \%)$. These data suggest that it may be necessary to consider both mixed infections and serological cross-reactions when simultaneous rises of antibody titres against these organisms are observed. Furthermore, other organisms that have been reported to cross-react with an antiLegionella antibody include various Pseudomonas spp. [13], Bordetella pertussis [14], Capnocytophaga [15] and Campylobacter spp. [16]. Cross-reactivity in MPAT with these organisms requires further investigation. These data may provide useful information for understanding the clinical significance of serological analysis, and to determine the criteria for MPAT in legionella pneumonia.

We thank Professor S. Kuwahara for critical reading of the manuscript and his helpful suggestions, and Dr F. G. Issa for expert editorial assistance. We also express our deep appreciation to Denkaseiken for kindly providing the MPAT reagents.

\section{References}

1. Edelstein PH, Meyer RD. Legionella pneumonias. In: Pennington JE (ed) Respiratory infections: diagnosis and management, 3rd edn. New York, Raven Press. 1994: 455-484.

2. Lind $\mathrm{K}$, Collins MT, Aalund O. Comparison of a microagglutination test and the indirect immunofluorescence test for Legionella antibodies in patients. Acta Pathol Microbiol Immunol Scand [Sect B] 1984; 92: 195-199.

3. Lennette DA, Lennette ET, Wentworth BB, French MLV, Lattimer GL. Serology of Legionnaires' disease: comparison of indirect fluorescent antibody, immune adherence hemagglutination, and indirect hemagglutination tests. J Clin Microbiol 1979 ; 10: $876-879$
4. Barka N, Tomasi J-P, Stadtsbaeder S. ELISA using whole Legionella pneumophila cells as antigen. Comparison between monovalent and polyvalent antigens for the serodiagnosis of human legionellosis. J Immunol Methods 1986; 93: 77-81.

5. Harrison TG, Taylor AG. A rapid microagglutination test for the diagnosis of Legionella pneumophila (serogroup 1) infection. J Clin Pathol 1982; 35: 1028-1031.

6. McDade JE, Shepard CC, Fraser DW et al. Legionnaires' disease. Isolation of a bacterium and demonstration of its role in other respiratory disease. $N$ Engl $J$ Med 1977; 297: 1197-1203.

7. Yabuuchi E, Saito A, Niki Y et al. [Determination of cut-off value of serum anti-Legionella antibody titer. Microplate agglutination test (MPAT)]. Kansenshogaku Zasshi 1997; 71: 116-124 [Japanese with English abstract].

8. Engleberg NC, Carter C, Weber DR, Cianciotto NP, Eisenstein BI. DNA sequence of mip, a Legionella pneumophila gene associated with macrophage infectivity. Infect Immun 1989; 57: $1263-1270$.

9. Koide M, Saito A, Yamashiro Y, Kusano N. [Diagnosis of legionellosis by microagglutination test - comparison to indirect immunofluorescent antibody method]. Kansenshogaka Zasshi 1996; 70: 1254-1258 [Japanese with English abstract].

10. Grady GF, Gilfillan RF. Relation of Mycoplasma pneumoniae seroreactivity, immunosuppression, and chronic disease to Legionnaires' disease. Ann Intern Med 1979; 90: 607-610.

11. Renner ED, Helms CM, Hall NH, Johnson W, Wong YW, Lattimer GL. Seroreactivity to Mycoplasma pneumoniae and Legionella pneumophila: lack of a statistically significant relationship. J Clin Microbiol 1981; 13: 1096-1098.

12. Liberman D, Porath A, Schlaeffer F, Lieberman D, Boldur I. Legionella species community-acquired pneumonia. A review of 56 hospitalized adult patients. Chest 1996; 109: 1243-1249.

13. Rodgers FG, Pasculle AW. Legionella. In: Balows A, Hausle WJ, Herrmann KL, Isenberg HD, Shadomy HJ (eds) Manual of clinical microbiology, 5th edn. Washington, DC, American Society for Microbiology. 1991: 442-453.

14. Ng V, Weir L, York MK, Handley WK. Bordetella pertussis versus non- $L$. pneumophila Legionella spp.: a continuing diagnostic challenge. J Clin Microbiol 1992; 30: 3300-3301.

15. Chen S, Hicks, L. Yuen M, Mitchell D, Gilbert GL. Serological cross-reaction between Legionella spp. and Capnocytophaga ochracea by using latex agglutination test. $J$ Clin Microbiol 1994; 32: 3054-3055.

16. Boswell TCJ. Serological cross reaction between Legionella and Campylobacter in the rapid microagglutination test. $J$ Clin Pathol 1996; 49: 584-586. 